\title{
Occupational injury risk among Australian paramedics: an analysis of national data
}

\section{Brian J Maguire DPH, MSA, EMT-P Professor, School of Medical and Applied Sciences \\ Peter F O'Meara BHA, MPP, PhD Professor of Rural and Regional Paramedicine ${ }^{2}$ \\ Richard F Brightwell PhD, BSc(Hons), PGCertEd Associate Professor ${ }^{3}$ \\ Barbara J O'Neil BSN, RN-OCN, PGCertNursEd Academic, School of Nursing and Midwifery! \\ Gerard J Fitzgerald MD, FACEM, FRACMA Professor of Public Health 4 \\ 1 Central Queensland University \\ Rockhampton, OLD. \\ 2 La Trobe University, Bendigo, VIC. \\ 3 School of Medical Sciences, \\ Edith Cowan University, Perth, WA. \\ 4 Queensland University of Technology, Brisbane, QLD. \\ b.maguire@cqu.edu.au}

MJA 2014; 200: 477-480 doi: 10.5694/mjal3.10941 mergency medical services (EMS) personnel (paramedics) are a critical component of both the emergency health care and the disaster response systems. In Australia, they respond to three million calls for emergency medical assistance each year. ${ }^{1-4}$ They are also involved in disaster planning, preparedness and response, as well as health promotion and injury prevention programs..$^{1,5}$

In 2007, Safe Work Australia (SWA) reported that paramedics have the sixth highest rate of occupational injuries; the report also showed that paramedics have the sixth highest rate of new mental stress claims for men. ${ }^{6}$

High rates have also been found in the United States, where Maguire identified a rate of occupational fatalities among paramedics of 12.7 per 100000 workers per year. This rate is more than twice the national average for all occupations and is comparable to those for police and firefighters. ${ }^{7}$ The rate of non-fatal injuries among US paramedics was 34.6 per 100 full-time workers per year, a rate more than five times higher than the national average for all workers. ${ }^{8}$ Other authors have found high rates of paramedic injuries, ${ }^{9-11}$ back injuries, ${ }^{8,12-14}$ transportation-related injuries and fatalities, $12,15-22$ and injuries resulting from violence against paramedics. 12,23

\section{Abstract}

Objective: To identify the occupational risks for Australian paramedics, by describing the rate of injuries and fatalities and comparing those rates with other reports.

Design and participants: Retrospective descriptive study using data provided by Safe Work Australia for the period 2000-2010. The subjects were paramedics who had been injured in the course of their duties and for whom a claim had been made for workers compensation payments.

Main outcome measures: Rates of injury calculated from the data provided.

Results: The risk of serious injury among Australian paramedics was found to be more than seven times higher than the Australian national average. The fatality rate for paramedics was about six times higher than the national average. On average, every 2 years during the study period, one paramedic died and 30 were seriously injured in vehicle crashes. Ten Australian paramedics were seriously injured each year as a result of an assault. The injury rate for paramedics was more than two times higher than the rate for police officers.

Conclusions: The high rate of occupational injuries and fatalities among paramedics is a serious public health issue. The risk of injury in Australia is similar to that in the United States. While it may be anticipated that injury rates would be higher as a result of the nature of the work and environment of paramedics, further research is necessary to identify and validate the strategies required to minimise the rates of occupational injury for paramedics.

It may be anticipated that the nature of paramedics' work and environment may increase their risk of occupational injury. Paramedics are exposed to the tragedies of life and death. Their workplace (a moving vehicle, difficult terrain, people's homes) is uncontrollable and the nature of their work involves considerable heavy lifting. However, many of the injuries incurred may be preventable. A more detailed understanding of paramedics' injury risks and of the strategies that may reduce these risks is necessary to ensure that the rates of injuries are minimised. The anticipated result is the improved health and wellbeing of paramedics, reductions in the human and financial cost of injury and, ultimately, more effective and efficient emergency medical care for all Australians.

Our study aimed to identify and highlight the rates of injury among Australian paramedics, and to create a foundation for the identification and validation of strategies that may reduce the impact of occupational injury. We identified specific rates of injury and compared these rates with

1 Injuries among Australian paramedics, 2000-2010 ( $n=6725) *$

\begin{tabular}{lcccc} 
Financial year & No. of serious cases ${ }^{\prime}$ & No. of paramedics & Injury rate $\neq$ & $95 \%$ Cl \\
\hline $2000-01$ & 560 & 6860 & 81.4 & $60.9-122.8$ \\
$2001-02$ & 565 & 5299 & 106.9 & $77.1-174.6$ \\
$2002-03$ & 565 & 7285 & 77.8 & $58.3-116.7$ \\
$2003-04$ & 550 & 7946 & 68.9 & $52.2-101.6$ \\
$2004-05$ & 610 & 7736 & 78.9 & $60.0-115.4$ \\
$2005-06$ & 745 & 10550 & 70.8 & $57.3-92.6$ \\
$2006-07$ & 725 & 12580 & 57.7 & $47.3-74.1$ \\
$2007-08$ & 755 & 9697 & 77.9 & $62.4-103.6$ \\
$2008-09$ & 825 & 8704 & 94.6 & $75.4-126.9$ \\
$2009-10 \S$ & 825 & 9701 & 85.0 & $67.7-114.2$
\end{tabular}

* Source: Safe Work Australia. Data adjusted to protect confidential information about employers and employees. Non-fatal injury categories with < 5 cases not included. † Rounded to the nearest 5 . $\ddagger$ Serious cases per 1000 workers. $\$$ Preliminary data. 
other occupations and jurisdictions for which data were available.

\section{Methods}

We conducted a retrospective descriptive study involving secondary analysis of aggregated data on occupational injury claims provided by officials from SWA. The data included all serious claims for which payments were made ("serious" was defined as a case that resulted in at least a week of lost work time). ${ }^{24}$

The data were paramedic injury cases reported to SWA for the period 2000-2010. The subjects did not include firefighters or non-paramedic flight-crew members. SWA has published the overall rate for paramedics, but the categorised data in this study have not been previously published. SWA provided all the data in Box 1 and Box 2. The data were analysed by BJ M, who computed the fatality rates and confidence intervals, as well as the proportions shown in Box 3 .

As the study involved secondary data analysis, it was categorised as exempt from ethics approval requirements by University of Maryland, Baltimore County protocol Y10BM08006.

\section{Results}

During the study period, Australian paramedics had an average rate of reported injury of 80 serious cases per 1000 workers per year, ranging from 57.7 to 106.9 (Box 1).

The mechanisms of injury of 6728 EMS personnel injury and fatality cases occurring between 2000 and 2010 are shown in Box 2. The largest category was muscular stress (eg, lifting and carrying) injuries with 2945 cases; many cases resulted from falls (655), vehicle accidents (150) and violence such as assault or bullying (170). There were eight occupational fatalities among paramedics (rate, 9.30 cases per 100000 workers per year; 95\% CI, 4.00-18.25). Of these, five were categorised as a vehicle accident (rate, 5.79 per 100000 workers per year; 95\% CI, 1.88-13.51).

\section{Discussion}

On average in Australia, one paramedic is killed every 2 years and 30 are seriously injured in transportation

2 Serious workers compensation cases among paramedics, by mechanism of injury, 2000-2010 $(n=6728) *$

Non-fatal ${ }^{\ddagger}$

Muscular stress while lifting, carrying, or putting down objects

$2945(44 \%)$

Muscular stress while handling objects other than lifting, carrying or putting down

Fall on the same level

$1080(16 \%)$

Muscular stress with no objects being handled

$490(7 \%)$

Work pressure

$375(6 \%)$

$200(3 \%)$

Unspecified mechanism of injury

$180(3 \%)$

Other mental stress factors

$175(3 \%)$

Fall from a height

$165(2 \%)$

Vehicle accident

$150(2 \%)$

Hit a stationary object

$110(2 \%)$

Exposure to traumatic event

$100(1 \%)$

Assaulted by a person or people

$100(1 \%)$

Stepping, kneeling or sitting on an object

$95(1 \%)$

Hit by a moving object

$65(1 \%)$

Contact with, or exposure to, biological factors of human

$55(1 \%)$

origin

Other and multiple mechanisms of injury

$55(1 \%)$

Trapped between stationary and moving objects

$50(1 \%)$

Hit by a person accidentally

$45(1 \%)$

Hit by a falling object

$40(1 \%)$

Exposure to workplace or occupational violence

$40(1 \%)$

Repetitive movement, low muscle loading

$35(1 \%)$

Work-related harassment and/or workplace bullying 30

Long-term exposure to sounds

Single contact with chemical or substance

Hit a moving object

20

Trapped by moving machinery

20

Contact with, or exposure to, biological factors

15

Harassment

Bitten by an animal

Other and unspecified contact with a chemical or substance

Total

Fatal

Vehicle accident

Other

Total

5

5

5

6720

* Source: Safe Work Australia. Data adjusted to protect confidential information about employers and employees. Table includes preliminary data for 2009-10. † Rounded to the nearest 5. ₹ Nonfatal injury categories with $<5$ cases not included.

incidents. Over 17 Australian paramedics a year receive serious injuries secondary to violence.

SWA reported on detailed rates for serious injuries per 1000 workers per year, by occupational groups, for 2008-09. ${ }^{24}$ During this period, the rate among paramedics was 94.6/1000 and the national average among all occupations in Australia was 13.0/1000. The rate among paramedics is more than seven times higher than the national average. The groups with the highest injury rates were skilled agricultural workers (82.9/1000), police officers (42.7/1000), road and rail transport drivers (33.1/1000), enrolled nurses (25.8/1000), and health carers and aides (20.0/1000). ${ }^{24}$ 
3 Number of non-fatal injuries among paramedics in Australia (2000-2010; $n=6720) *$ compared with the United States $(2003-2007 ; n=21690),{ }^{12}$ by main categories of injury

No. of cases (\%)

\begin{tabular}{|c|c|c|}
\hline \multirow[b]{2}{*}{ Injury category } & \\
\hline & Australia & US \\
\hline Muscular stress while lifting, carrying, or putting down objects & $2945(44 \%)$ & $8040(37 \%)$ \\
\hline Fall on the same level & $490(7 \%)$ & $1650(8 \%)$ \\
\hline Fall from a height & $165(2 \%)$ & $550(3 \%)$ \\
\hline Vehicle incidents & $150(2 \%)$ & $1940(9 \%)$ \\
\hline Hit a stationary object & $110(2 \%)$ & $560(3 \%)$ \\
\hline Assaulted by a person or people & $100(1 \%)$ & $530(2 \%)$ \\
\hline Hit by a moving object & $65(1 \%)$ & $730(3 \%)$ \\
\hline
\end{tabular}

Compared with the national average of 1.6 fatalities per 100000 workers per year, the rate for paramedics was 9.3 per 100000 (relative risk, 5.8 [95\% CI, 2.9-11.6]). Safe Work Australia notes that the industry division with the highest rate is agriculture, forestry and fishing (9.1 per 100000 workers), and that the occupation group with the highest rate is intermediate production and transport workers (6.0 per 100000 workers).24 For fatal vehicle accidents, the rate for paramedics is 5.8 per 100000 workers (relative risk, 11.6 [95\% CI, 4.8-27.9]), compared with the national average of 0.5 per 100000 for all workers. ${ }^{24}$

The only other national data found for paramedics were in published research from the US.12 Cases and proportions by mechanism of injury in Australia and the US are shown in Box 3 . The US study was based on aggregate data provided by the US Bureau of Labor Statistics; these are mandatory data collected from all states. In both countries, lifting accounts for the greatest proportion of injuries. Differing case definitions between the two countries preclude a direct comparison of injury rates.

Although female paramedics were shown to have a disproportionately high risk of occupational injuries in the US, 15 insufficient data exist to quantify the risks among female paramedics in Australia.

There are limitations to this study. The SWA data are only for serious injuries resulting in claims approved for compensation, thereby reducing the case numbers. Nor do they include incident data that might help to explain the circumstances and causes of the injury, and that may help to identify what might be done to prevent injuries.

The broad data available from SWA do help to identify the scope and nature of risks in the Australian population. However, more specific data are needed for detailed occupational risk studies. Future research should seek to include personnel data, source of injury, event information, disposition and other information such as seatbelt usage. These are data that are likely collected and owned by the ambulance agencies.

Additionally, the development and adoption of sound injury prevention interventions requires work directed at standardisation of data collection, reliable data analyses, development of interventions, testing of interventions, publication of findings, and large-scale deployment of successful interventions. The same research tools that we use to determine whether a medication is reliable enough to save the lives of our patients should be used to determine that interventions are reliable enough to save the lives of our paramedics.

Any efforts to reduce occupational injuries and fatalities among paramedics must be done through partnerships between EMS agencies and researchers. The agency's detailed data would allow, for example, evaluation of the impact of factors such as work hours or differences by sex or event. Data such as these could be used to help develop interventions, inform conclusions and support recommendations for future interventions. Interventions that may reduce risks for paramedics might also be effective for other occupational groups including emergency services personnel or health care workers and physicians who may be asked to render care during disasters, on roadsides or in public.

This is the first study to examine the risks of fatalities and injuries among Australian paramedics. It reinforces earlier findings from the US of the high risk of occupational injuries and fatalities among paramedics.

The analysis demonstrates that the paramedic profession is one of the most dangerous occupations in Australia. No other group identified by SWA has a higher injury rate than paramedics. Fatalities result largely from transportation events. The highest proportion of non-fatal injuries is associated with lifting.

Future researchers should focus on detailed analysis of the patterns of injury and of the factors that appear to contribute to those injuries, in order to identify and evaluate injury-prevention strategies.

Acknowledgements: This project was supported by the Australian-American Fulbright Commission and the Australian Government Collaborative Research Networks program. We thank Keith Mallett and the data and analysis section of SWA for their critical data contributions.

Competing interests: No relevant disclosures.

Received 21 Jul 2013, accepted 12 Nov 2013.

1 Maguire BJ, Walz BJ. Current emergency medical services workforce issues in the United States. J Emerg Manag 2004; 2: 17-26.

2 Fitzgerald G, Tippett V, Schuetz M, et al. Queensland emergency medical system: a structural and organizational model for the emergency medical system in Australia. Emerg Med Australas 2009; 21: 510-514.

3 Maguire BJ, Dean S, Bissell RA, et al. Epidemic and bioterrorism preparation among emergency medical services systems. Prehosp Disaster Med 2007; 22: 237-242.

4 Australian Government Productivity Commission. Emergency management. Report on Government Services 2011, Ch. 9. http://www.pc.gov.au/_data/assets/pdf_ file/0011/105320/037-chapter9.pdf (accessed Apr 2011).

5 Harrawood D, Gunderson MR, Fravel S, et al. Drowning prevention. A case study in EMS epidemiology. JEMS 1994; 19: 34-38, 40-41.

6 Safe Work Australia. Compendium of workers' compensation statistics Australia 200405. 2007. http://www.safeworkaustralia. gov.au/sites/SWA/about/Publications/ Documents/423/Compendium_Workers Compensation_Statistics_Australia_2004_05. pdf (accessed May 2013).

7 Maguire BJ, Hunting KL, Smith GS, Levick NR. Occupational fatalities in emergency medical services: a hidden crisis. Ann Emerg Med 2002; 40: 625-632.

8 Maguire BJ, Hunting KL, Guidotti TL, Smith GS. Occupational injuries among emergency medical services personnel. Prehosp Emerg Care 2005; 9: 405-411.

9 Gershon RR, Vlahov D, Kelen G, et al. Review of accidents/injuries among emergency medical services workers in Baltimore, Maryland. Prehosp Disaster Med 1995; 10: 14-18. 
10 Sterud T, Ekeberg $\emptyset$, Hem E. Health status in the ambulance services: a systematic review. $B M C$ Health Serv Res 2006; 6: 82.

11 Reichard AA, Marsh SM, Moore PH. Fatal and nonfatal injuries among emergency medical technicians and paramedics. Prehosp Emerg Care 2011; 15: 511-517.

12 Maguire BJ, Smith S. Injuries and fatalities among emergency medical technicians and paramedics in the United States. Prehosp Disaster Med 2013; 28: 376-382.

13 Schwartz RJ, Benson L, Jacobs LM. The prevalence of occupational injuries in EMTs in New England. Prehosp Disaster Med 1993; 8: 45-50.

14 Reichard AA, Jackson LL. Occupational injuries among emergency responders. Am J Ind Med 2010; 53: 1-11.

15 Maguire BJ. Transportation-related injuries and fatalities among emergency medical technicians and paramedics. Prehosp Disaster Med 2011; 26: 346-352.

16 Maguire BJ. Ambulance safety in the US. J Emerg Manag 2003; 1: 15-18.

17 Maguire BJ, Kahn CA. Ambulance safety and crashes. In: National Association of EMS Physicians; Cone DC, editor. Emergency medical services: clinical practice and systems oversight. Dubuque, lowa: Kendall Hunt Publishing, 2009.

18 Maguire BJ, Porco FV. EMS and vehicle safety. Emerg Med Serv 1997; 26: 39-43.

19 Kahn CA, Pirrallo RG, Kuhn EM. Characteristics of fatal ambulance crashes in the United States: an 11-year retrospective analysis. Prehosp Emerg Care 2001; 5: 261-269.

20 Pirrallo RG, Swor RA. Characteristics of fatal ambulance crashes during emergency and non-emergency operation. Prehosp Disaster Med 1994: 9: 125-132.
21 Becker LR, Zaloshnja E, Levick N, et al. Relative risk of injury and death in ambulances and other emergency vehicles. Accid Anal Prev 2003; 35: 941-948.

22 Maguire BJ, Hunting KL, Guidotti TL, Smith GS The epidemiology of occupational injuries and illnesses among emergency medical services personnel. Ann Arbor, Mich: ProQuest, 2004.

23 Mechem CC, Dickinson ET, Shofer FS, Jaslow D. Injuries from assaults on paramedics and firefighters in an urban emergency medical services system. Prehosp Emerg Care 2002; 6: 396-401.

24 Safe Work Australia. Compendium of workers' compensation statistics Australia 2010-11. 2013. http://www.safeworkaustralia.gov. au/sites/swa/about/publications/pages/ compendium-2010-11 (accessed May 2013). 